\title{
The academic transitional experiences of masters' students at the University of the Western Cape
}

\begin{abstract}
Authors:
Jeffrey C. Hoffman ${ }^{1}$

Hester Julie ${ }^{1}$

Affiliations:

${ }^{1}$ School of Nursing, University of the Western Cape,

South Africa

Correspondence to:

Hester Julie

Email:

hjulie@uwc.ac.za

Postal address:

Private Bag X17, Modderdam

Road, Bellville, South Africa

Date:

Received: 02 Aug. 2011

Accepted: 15 June 2012

Published: 24 Aug. 2012

How to cite this article:

Hoffman, J.C. \& Julie,

H., 2012, 'The academic

transitional experiences of

masters' students at the

University of the Western

Cape', Curationis 35(1), Art.

\#33, 8 pages. http://dx.doi.

org/10.4102/curationis.

v35i1.33
\end{abstract}

C 2012. The Authors.

Licensee: AOSIS

OpenJournals. This work

is licensed under the

Creative Commons

Attribution License.
Transition has been a major focus of educational institutions. However, most of the research into student transition focuses on the challenges related the transition from high school to university. Not much emphasis has been placed on the transition from undergraduate to postgraduate studies, despite the steadily increasing postgraduate enrolment rates in higher education institutions. The discrepancy between the enrolment and completion rates is an indication that postgraduate students are facing transitional challenges when engaging with postgraduate studies. The aim of this research study was to describe the academic transitional experiences of masters' students in the Faculty of Community Health Sciences at the University of the Western Cape. The objectives were to determine the academic preparedness of postgraduate students, to explore their primary motivations for pursuing postgraduate studies, and to assess their utilisation of the available support services at UWC.

A quantitative, exploratory, descriptive research design was employed. A cross-sectional survey was conducted with masters' students during 2009, using convenience sampling. Data was statistically analysed using the SPSS to provide descriptive statistics.

The majority of the sample indicated a lack of academic preparedness, even though most of them had a bachelor's degree. The primary reasons listed as motivation for master's study were to improve knowledge and reaching self-actualisation. The majority is still eager to complete their studies. Most support systems were utilised and students rated these services as a positive experience that facilitates smooth academic transition. However, concerns are that not many students utilised the academic writing centre and those who did, rated the overall service as average. One of the main recommendations was that a research culture needs to be established at undergraduate level, as this would give students greater exposure to research activities.

\section{Introduction}

The South African Government was concerned about the discrepancy between postgraduate enrolment and graduation rates. The Department of Education (DoE) remarked that the average graduation rate remained at 15\% between 1993 and 1998 despite increased enrolment rates in higher education institutions (DoE 1997:12). The National Plan for Higher Education South Africa (NPHESA) was therefore released in 2001 to provide higher education institutions (HEIs) with the necessary support to engage in institutional and organisational restructuring to improve the graduate rates (Ministry of Education 2001). The substantial growth between 1990 and 2005 was evidence that HEIs have been implementing the NPHESA (CHE 2009:2).

However, research on postgraduate students at South African universities indicates that whilst enrolments are steadily increasing, graduation rates do not correlate with these (CHE 2009:9; Walters \& Koetsier 2006:100). Nationally, enrolment at postgraduate level increased almost twofold from 1990 to 2005. However, as a proportion of total enrolment, the number of postgraduate students declined over this period from 31.3\% to 26.9\% (DoE 2007:3). Between 2001 and 2004, the average attrition rate in postgraduate programmes was 18.5\% (CHE 2010b:25-26). Likewise, students enrolled for masters' degrees increased at an average annual rate of $4.4 \%$ between 2000 and 2003, but declined between 2003 and 2005. The Council on Higher Education (CHE) stated that students struggle to complete postgraduate studies in the minimum prescribed time of 3 years (CHE 2010a:3). It is a major concern that the latter observation applied to 37\% of the national cohort in 2005 (CHE 2009:13). It can thus be postulated that these students are encountering transitional challenges.

\section{Aspects related to postgraduate academic transition}

Academic transition is defined as the process of moving from one set of circumstances to another (Nash \& Sacre 2009). 
Although transition is imperative, the degree of adjustment to the academic environment and academic roles is a significant predictor of students' academic success. Earwaker (1992:50) terms this adjustment phase 'transition' because it refers to 'strategies people use in coping with change, like entering academic life' (Laboone 2006:13). Brown and Holloway (2008) posit that transition is best understood as a process of change that is especially stressful at first. However, problems tend to decrease over time as postgraduate students become familiar with the academic demands and adapt to the situation. The different types of transition are briefly differentiated below because it is such a broad concept.

Personal-emotional transition is related to the emotional well-being of students (Brown \& Holloway 2008). It refers to feelings of disorientation, depression, isolation and powerlessness that students experience in response to academic stress (Poyrazli \& Grahame 2007).

Social transition refers to the lack or malfunction of social support systems, which should be made available for students. The above authors therefore recommend student mentoring programmes as a possible social support system as this would contribute towards better psychosocial adjustment and smoother academic transition.

Academic transition for postgraduate students means that they often need to readapt to academia when returning to postgraduate studies after they have completed their undergraduate studies. In this study, academic transition was measured in terms of students'academic preparedness, their motivation prior to enrolment and their utilisation of support systems.

\section{Problem statement}

The trend described by CHE is also observed at the University of the Western Cape (UWC). Although UWC (1998) aligned its strategic research plan with the national imperative by increasing postgraduate enrolment from $9 \%$ in 1998 to $20 \%$ in 2000. Walters and Koetsier (2006:100) postulate that both situational and institutional barriers form a major constraint to academic transition. They state that inconsistencies in the enrolment and throughput rates is evidence that students experience difficulties in adjusting to the learning environment. These adjustment difficulties or transitional challenges include concerns about academic writing skills; organisation (using resources like the library, computers and statistics, time management and available resources); the supervisory relationship; and other general aspects related to studies (Symons 2006).

\section{Research aim and objectives}

The primary aim of this study was therefore to explore the academic transitional experiences of masters' students in the Faculty of Community Health Sciences (FCHS) at UWC by addressing the following objectives.
The objectives were formulated to:

- determine the academic preparedness of masters' students of the FCHS at UWC.

- explore their primary motivations for pursuing further studies.

- investigate their utilisation of the available support services at UWC.

\section{Research methods and design Design}

A cross-sectional, descriptive design was used to explore and describe the academic transitional experiences of masters' students.

\section{Study population and sampling}

The study population comprised students at master's level in the FCHS enrolled during 2009, excluding students in the first year of their master's degree. The FCHS includes the Schools of Nursing and Public Health, and the Departments of Social Work, Physiotherapy, Human Ecology, Psychology, Occupational Therapy, Sports and Recreational Science and Human Ecology and the School of Natural Medicine. Convenience sampling was used due to the small size of the population (374) and to ensure cross-sectional inclusion.

\section{Data collection tool}

A self-administered, structured questionnaire was developed by drawing on Symons' (2006) Commencing Postgraduate Course Survey. The 25 questions were divided into four sections, namely, demographics; the academic preparedness of masters' students, their primary motivations for studying and their utilisation of available support services at UWC.

\section{Response rate}

The questionnaire was emailed to 374 students registered at the FCHS for a master's degree. During the data collection period, 175 opened the e-mail and only 57 students completed the questionnaire, in spite of three follow-ups. This low response rate of $15.2 \%$ constitutes a non-response sampling error, according to De Vos, Strydom, Fouche and Delport (2005:196). Thus the results of this study cannot be generalised to other masters' students at UWC.

\section{Data analysis}

Data analysis was conducted using SPSS version 16. Descriptive statistics were used to summarise the data in tabular and graphical format.

\section{Ethical considerations}

The ethical principle of beneficence was adhered to during the research, where potential benefits of the research to individuals and society were maximised and potential harm was minimised (De Vos et al. 2005:58). This study posed no threat to the safety and dignity of participants. 
Confidentiality was protected by ensuring easy and safe participation, and confidentiality of participants as well as their responses. The researcher sent an email to himself and entered the participants' addresses in the blind copy field (BC) to ensure that the participants would not be able to see who else the email was addressed to. Raw data were secured and subsequently destroyed according to the legal requirements of UWC. The participants had the right of selfdetermination, in the sense that participation in the research was voluntary and they had the right to withdraw at any stage. Inappropriate or coercive incentives were not utilised. Informed consent to participate in the research was requested personally during the January and February 2009 registration period and electronically during the July and August 2009 data collection period. Participants were informed that if they returned the completed questionnaire, their consent to participate was automatically given. Information about the study was provided in simple terminology and included the purpose of the research and duration of participation. Permission and ethical clearance were obtained from Faculty and Senate Higher Degrees Committees, the heads of the departments concerned and the Registrar (Academic) of UWC.

\section{Reliability and validity}

To ensure validity of the instrument, the questionnaire was adapted from that used by Symons (2006) in a similar study and circulated amongst academic researchers at the UWC School of Nursing to assess construct, content and face validity. The adapted questionnaire was found on the public domain, therefore it was not necessary to obtain permission. It was then pilot tested with 10 masters' students in Nursing Education during January 2009.

\section{Discussion of results}

The study population consisted of 374 masters' students who were registered during the 2009 academic year. All masters' students in the FCHS who met the inclusion criteria had the opportunity to take part. A total of $57(15.2 \%)$ consented to participate in the study and successfully completed the selfadministered questionnaire electronically.

The findings are discussed in the following sequence: the socio-demographic profile, academic preparedness of students, motivation for pursuing further studies and utilisation of available institutional support services.

\section{Socio-demographic information}

The demographic profile included marital status, number of dependents, employment status, combined household income, full- or part-time studies, age and language. Table 1 shows an overview of the demographic profile of the sample.

\section{Socio-demographic characteristics of respondents}

The following variables below were clustered because they identify social support systems, related to social transition (Poyrazli \& Grahame 2007).
Marital status, number of dependants, employment status, full or part time studies, and household income

The majority were married (27, or $47.4 \%)$, had one to two dependants $(28$, or $49.2 \%)$, worked full-time $(30$, or $52.6 \%)$, studied part-time $(36$, or $63.2 \%)$ and $(17$, or $29.8 \%$ ) had a combined income below R60 000 per annum. These findings could indicate that students also have to deal with personal, emotional and social transitions in addition to the academic transition (Poyrazli \& Grahame 2007).

Age and language are important predictors of academic success (CHE 2009:21). See Table 2 for a summary.

\section{Age}

Most of the sample (34, or $60 \%)$ were younger than 30 years, with the majority (28, or $49.1 \%$ ) aged between 24 and 30 years. This finding differs from the national statistics which identified the mean age of masters graduates as 34 years and the the mean age for enrolment for postgraduate studies to be 30 years of age (CHE 2009:21).

This indicates that students enrol for postgraduate studies soon after completing their undergraduate studies. According to the Australian findings, this places them in a high-risk category for non-completion as postgraduate students in the

TABLE 1: Socio-demographic characteristics of sample.

\begin{tabular}{llll}
\hline Variable & Responses & $f$ & $\%$ \\
\hline Marital status & Never Married & 25 & 43.9 \\
& Married & 27 & 47.4 \\
& Divorced & 4 & 7 \\
Number of dependants & Other & 1 & 1.8 \\
& None & 24 & 42.1 \\
& One & 14 & 24.6 \\
& Two & 14 & 24.6 \\
& More than two & 5 & 8.8 \\
Employment status & Unemployed & 8 & 14.1 \\
& Employed & 30 & 52.6 \\
& Employed (part-time) & 3 & 5.3 \\
& Employed (contract) & 16 & 28.1 \\
Full-time Part-time & Full-time & 21 & 36.8 \\
& Part-time & 36 & 63.2 \\
Combined household income & R0-R60 000 & 17 & 29.8 \\
& R60 001-R120 000 & 16 & 28.1 \\
& R120 001-R150 000 & 9 & 15.8 \\
& More than R150 000 & 15 & 26.3 \\
\hline
\end{tabular}

Valid $N$ (List-wise) 57; $f$, Frequency.

TABLE 2: Age and language of sample.

\begin{tabular}{llll}
\hline Variable & Responses & $f$ & $\%$ \\
\hline Age in years & $<23$ & 6 & 10.5 \\
& $24-30$ & 28 & 49.1 \\
& $31-35$ & 5 & 8.8 \\
Language & $>35$ & 18 & 31.6 \\
& English & 21 & 35.1 \\
& Afrikaans & 19 & 33.1 \\
& African languages & 4 & 7.0 \\
& Other languages & 14 & 24.6 \\
\hline
\end{tabular}

Valid $N$ (List-wise) 57; $f$, Frequency. 
age group 25 to 29 years have the lowest predicted probability of completion (Martin, Maclachan, Karmel \& Department of Education, Training and Youth Affairs 2001:8-9).

Language was investigated, because Poyrazli and Grahame (2007) submit that English language proficiency is an important predictor of success at English-medium universities.

\section{Language}

The findings indicate that English is not the dominant home language for $64.9 \%$ of the respondents. The distribution is almost equal between English (35.1\%), Afrikaans (33.3\%), and African or other languages (31.6\%). African languages refer to the nine official African languages in South Africa, such as isiXhosa, isiZulu and seTswana, whilst 'other' languages include French, Portuguese, etc.

If we agree with Poyrazli and Grahame (2007:29-30) that language difficulties are of special importance for international students, it can be concluded that English, as the medium of instruction at UWC, contributes to the academic transitional challenges that students face.

The overall socio-demographic profile of the respondents indicates that they face challenges even before they enter their academic programme. This finding confirms Laboone's (2006) statement that personal, emotional and social transition are interwoven with academic transition.

\section{Academic preparedness}

The students' academic preparedness was explored, because Ofori and Charlton (2002:512) mention that previous tertiary experiences influence throughput and attrition rates. In this study, academic preparedness refers to the students' preparation for postgraduate studies as measured by scholarly activities prior to enrolment. These include previous qualifications, experience in a field of expertise, understanding of the research process and involvement in scholarly activities.

\section{Qualifications prior to enrolment}

A small percentage in the sample $(2 / 56$, or $3.6 \%)$ had only a 4-year diploma, four (7.1\%) had a 4-year diploma plus an additional short course, 41 (73.2\%) had a bachelor's degree, and nine $(16.1 \%)$ were in possession of a bachelor's degree plus a postgraduate diploma. A total of $89.3 \%(n=50)$ of the postgraduate respondents had a basic degree. This means that $10.7 \%$ did not have a basic degree and must have entered the university via the RPL route.

Ofori and Charlton (2002:512) state that entry qualifications have a direct impact on academic performance, therefore the expectation is that this sample should do well academically.

\section{Experience in field of expertise}

The majority had more than 4 years' experience $(23 / 56$, or $41.1 \%)$, six $(10.7 \%)$ had 4 years' experience, $11(19.6 \%)$ had 2 to 3 years of experience, ten (17.9\%) had only 1 year of experience, and six (10.7)\% had no experience. Slightly more than half of the sample $(33$, or $58.9 \%$ ) had 4 years' or less experience in their field of study. This shows that these postgraduate students are not very experienced when enrolling for postgraduate studies.

\section{Understanding of the research process}

Respondents were asked to indicate if they had no understanding of the research process, or whether they had gained understanding of the process during undergraduate studies or by attending other post basic programmes. Most of the respondents (64.9\%) had gained an understanding during their undergraduate studies, $21.1 \%$ by attending a programme, whilst $14 \%$ had no understanding of what research entailed.

Nichols and Miller (1994) state that students motivation and willingness to engage in learning are influenced by prior learning experiences and academic success.

\section{Scholarly activities prior to enrolment}

Scholarly activities in this study referred to involvement in research activities and production of publications and research papers prior to current academic enrolment.

Most students in this study entered their postgraduate programmes without having previously been involved with research activities. A mere six (10.5\%) had produced research papers or publications prior to enrolment. Only five $(8.8 \%)$ indicated that they had been actively involved with research activities and 11 (19.3\%) had attended research conferences prior to enrolment.

This finding is a concern, because although $89.3 \%$ of the respondents had a bachelor's degree, only six $(10.5 \%)$ reported having produced research papers or other publications prior to enrolment. This suggests that, even though most of the sample had been exposed to the research process, they had not really developed a culture of research before returning for further studies. This result confirms Dawson's finding, where postgraduate students identified the following aspects as development needs: conference presentations, publications and socialising in an academic environment and self-reflection (Dawson 1994).

Nichols and Miller (1994) identified a link between motivation and academic preparedness in stating that students' academic preparedness for further study, their prior learning experiences and their academic success affect their self-belief, which in turn influences their motivation and willingness to engage in learning (Nichols \& Miller 1994).

\section{Motivation}

The researcher argues that many of the students' academic transitional challenges are linked to their primary motivation for pursuing further studies. In this study, motivation was measured by the following subscales: confidence regarding 
chosen academic programme, meaning of postgraduate studies, reason for pursuing postgraduate studies, and eagerness to complete the programme.

\section{Confidence regarding choice of academic programme}

In this study, $31(54.4 \%)$ of the respondents were sure about their chosen academic programme, whilst the others $(45.6 \%)$ were either unsure or had doubts. This confirms the finding of Moutisios-Rentzos and Simpsom (1997:335) that 'postgraduates may be more likely to have chosen their route for the sake of interest and be less clear about the pragmatic worth of the qualification'.

\section{Main reason for pursuing postgraduate studies}

Motivational factors, according to Nichols and Miller (1994), may range from self-actualisation, improving social status to expansion of knowledge. Therefore, students were asked about these factors in the questionnaire. More than half of the respondents $(33 / 57$ or $57.8 \%)$ indicated that they wanted to expand their body of knowledge, and a smaller proportion $(12 / 57$ or $21.1 \%)$ said they wanted to obtain a master's qualification and to secure better employment and compensation.

\section{Meaning of postgraduate studies to student}

Almost a third of the respondents (37/57 or $64.9 \%)$ indicated that postgraduate studies offered them a chance to improve their existing body of knowledge, whilst 19 (33.3\%) indicated that it meant 'reaching self-actualisation'. Only one respondent $(1.8 \%)$ indicated that studies offered 'a chance to get involved with influential people'.

Thus the primary motivation of postgraduate students appears to be closely related to their intrinsic motivation, except for the one response that was extrinsically motivated. This result is consistent with the results indicating that career and educational aspirations are the main reasons why postgraduates choose to return to university after undergraduate studies (Arquero, Byrne, Flood, and Gonzalez 2005).

Eagerness to complete studies was measured because motivation is closely linked to students' perseverance and goal commitment (Arquero et al. 2005).

\section{Eagerness to complete academic programme}

Respondents were asked to indicate if they agree with a statement that they have lost their eagerness to complete their studies. Fourteen (24.6\%) strongly disagreed, 24 (42.1\%) disagreed, 17 (29.8\%) agreed and two (3.5\%) strongly agreed. The findings revealed that the majority of the sample $(38 / 57$ or $66.7 \%$ ) were still motivated to complete their studies. However, a third of the sample, $(19 / 57$ or $33.3 \%)$ were not motivated at the time of completing the questionnaire.

Students' perseverance and goal commitment (Arquero et al. 2005:115) are intricately linked to the nature and strength of their desire to engage in an activity (Lovitts 2005:148), in this case, completing their studies. Thus, this finding can be interpreted as a threat to their completing their academic programme within the minimum timeframes.

\section{Duration of current studies}

Respondents were asked how long they have been in their current academic programme. The majority (40 or $70.2 \%$ ) indicated less than 2 years, whilst 17 (29.8\%) indicated the duration to be more than 2 but less than 5 years.

According to the $\mathrm{CHE}$, the average number of years to complete a masters' degree in the Health Sciences is about 3.5 years, and $37 \%$ of students at South African HEIs do not graduate within the minimum time (CHE 2009:13). The results of this study give the idea that a trend could be developing that is consistent with the findings of the CHE.

Lowe and Cook (2003) suggest that students who are willing to seek academic support are likely to be highly motivated in academia. Laboone (2006) further states that a general principle might be to provide services that are easily available to students.

The study therefore explored whether students optimally utilised available institutional support services.

\section{Utilisation of available institutional support services}

In this study, the following support services were explored: an orientation programme, a postgraduate enrolment and throughput (PET) programme, library services, the academic writing centre, individual academic support, writing coaches and/or mentors and information communication services (ICS).

Symons (2006) suggests that a proper orientation programme for students entering postgraduate studies for the first time must be in place to minimise academic transitional challenges.

\section{Orientation Programme}

This study explored whether students participated in an orientation programme and how they would rate it. The majority (40/57 or $70.2 \%)$ of the respondents stated that an orientation programme was in place soon after enrolment. However, $15(26.3 \%)$ did not attend, $25(43.9 \%)$ rated it as informative, $14(24.6 \%)$ considered it to be superficial, and three $(5.3 \%)$ not helpful.

The reasons why these postgraduates did not attend the orientation programme were not determined in this study and can be regarded as a limitation of this study, because (Rumsey 2004:92) suggests that support services for postgraduates, as discussed, have been somewhat ad hoc.

Laboone (2006) acknowledges that facilitating the integration of students into the academic culture of the institution would help with issues of academic transition. 


\section{Rating of Available Institutional Support Services}

Respondents were requested to rate the services, if utilised, according to a 4 -point Likert scale (i.e., ' 1 ' = poor; ' 2 ' = average; ' 3 ' = good; ' 4 ' = excellent), for all questions in this section except orientation.

\section{The PET programme}

The PET programme is a programme offered by UWC with the intention to influence positively the completion rate and to instill in postgraduate students a research culture. It is committed to increasing the throughput rate in the minimum possible time (University of the Western Cape, 2007).

The majority (50 or $87.7 \%$ ) utilised the PET programme whilst $7(12.3 \%)$ did not make use of this service. The services were rated as average (22/57 or $38.6 \%)$, good (18 or $31.6 \%$ ) and excellent (7 or $12.3 \%$ ).

\section{Library Services}

All 57 students made use of the library services. The services were rated as poor by one student $(1.8 \%)$, average by 17 (29.8\%), good by $23(40.4 \%)$ and as excellent by $16(28.1 \%)$.

The library service is highly rated, as the majority (39 or $68.5 \%$ ) of respondents rated the services of the library as good or excellent.

\section{Academic Writing Centre}

The Writing Centre Project was established at UWC in 1994 to assist and develop academic writing skills in students (Clarence 2009:01).

The majority (40 or $70.2 \%$ ) used this service, whilst 17 (29.8\%) did not. The services were rated as poor by two students $(3.5 \%)$, average by $23(40.4 \%)$, good by ten $(17.5 \%)$ and excellent by five $(8.8 \%)$.

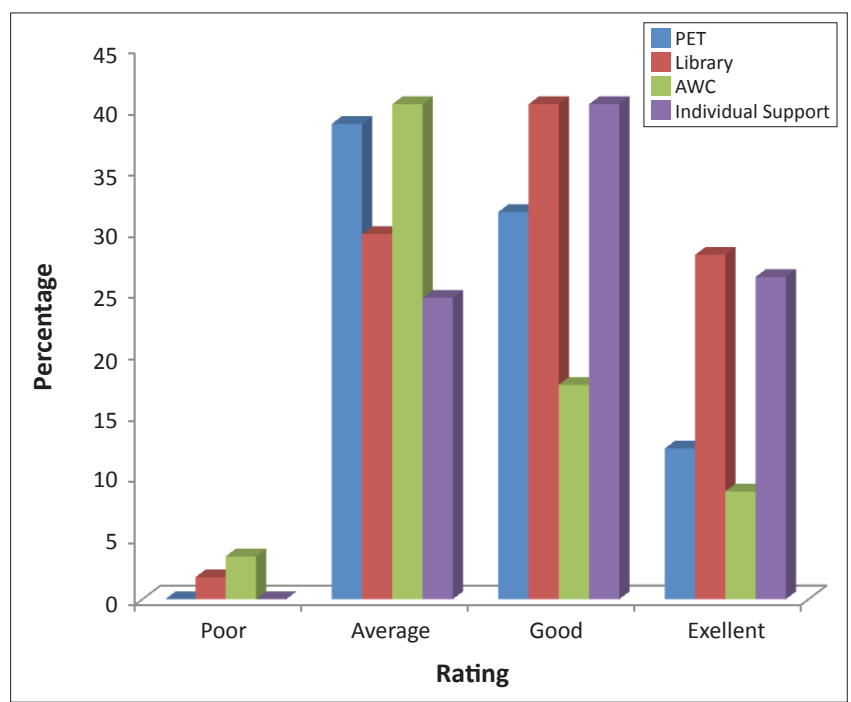

FIGURE 1: Rating of support services.

\section{Individual academic support}

A study conducted by Ofori and Charlton (2002) found that seeking out one-on-one academic support services and entry qualifications has a direct, positive influence on a student's performance. They found that support-seeking had a direct impact on performance.

In this study, the researchers wanted to ascertain whether postgraduates make use of consultations with their research supervisor. The results revealed that most respondents (52 or $91.2 \%$ ) did use this service. The services were rated as average by $14(24.6 \%)$, good by $23(40.4 \%)$ and $15(26.3 \%)$ rated them as excellent. These results thus correlate with those in the study by Ofori and Charlton (2002:508) and indicate that students do depend on individual sessions with their supervisors and academics.

Laboone states that it is imperative that positive relationships be established between the student and the institution, because facilitating the integration of students into the academic culture of the institution would help with issues of academic transition. A general principle might be to provide maximum services that are easily available to students (Laboone 2006).

The finding thus confirms that UWC has addressed the concern about inadequate distribution of services at systems level (Walters \& Koetsier 2006:13). It is apparent that UWC has put in place different support systems to assist postgraduate students with their academic transition. Respondents rated highly the library services, PET and individual academic support. Using these services was a positive experience that facilitated smooth academic transition. However, a concern is that not many respondents have utilised the academic writing centre and that it was overall rated as average. This is especially true in light of the finding that English was the home language of only a third of the respondents.

\section{Summary}

The literature reviewed revealed that postgraduate students at UWC experienced difficulties in adjusting to the learning environment, as indicated by inconsistencies in the enrolment and throughput rates, which are an indication that students are experiencing academic transitional issues (Walters \& Koetsier 2006:97). The academic preparedness of students was explored, because Ofori and Charlton (2002:512) mention that previous tertiary experiences influence throughput and attrition rates. In this study, academic preparedness referred to the students' preparation for postgraduate studies as measured by scholarly activities prior to enrolment. The latter referred to previous qualifications, experiences in a field of expertise, understanding of the research process and scholarly activities.

Nichols and Miller (1994) identified a link between motivation and academic preparedness in stating that 
students' academic preparedness for further study, their prior learning experiences and their academic success affect their self-belief, which in turn influences their motivation and willingness to engage in learning (Nichols \& Miller 1994). The researcher therefore argued that many of the students' academic transitional challenges were linked to their primary motivation for pursuing further studies. Motivation was measured by the following subscales: confidence about the chosen academic programme, meaning of postgraduate studies, reason for pursuing postgraduate studies, and eagerness to complete the programme.

Laboone (2006) states that it is imperative that positive relationships be established between the student and the institution because facilitating the integration of students into the academic culture of the institution would help with issues of academic transition. He argues for the provision of services that are easily available to students (Laboone 2006).

The findings thus confirm that UWC has addressed the concern about inadequate distribution of services at a systems level (Walters \& Koetsier 2006:13). It is apparent that UWC has put in place different support systems to assist postgraduate students with their academic transition. The majority of the sample is motivated and still eager to complete their studies; most of them utilise most of the available support systems, which are highly rated, and using these services was generally a positive experience that facilitated smooth academic transition.

However, concerns are that not many respondents have utilised the academic writing centre and that it was overall rated as average; English was the home language of only a third of the sample; the socio-demographic profile indicates that students face possible personal, emotional and social transitional issues which may compound academic transitional challenges (Laboone 2006); although most have a bachelor's degree, they have not developed a research culture prior to enrolment.

\section{Limitations of the study}

Postgraduate transition is a multifaceted topic, which includes academic, personal-emotional and social transition issues. This study focused only on academic transition. The small size of the study population and the low response rate make it inappropriate to generalise findings.

\section{Recommendations}

A research culture needs to be established at undergraduate level; this would give students more exposure to research activities.

Admission criteria for postgraduate students need to include some criteria related to research experience.

Orientation programmes should be targeted at all postgraduate students, and their effectiveness should be revisited.
Utilisation of support services should be further investigated. There needs to be a focus on how students engage with these services.

\section{Acknowledgements}

Acknowledge CENTALS for financing language editing.

\section{Competing interests}

The authors declare that they have no financial or personal relationship(s) which may have inappropriately influenced them in writing this article.

\section{Authors' contributions}

H.J.C. (University of the Western Cape) conducted the study. J.H. (University of the Western Cape) supervised the study.

\section{References}

Arquero, J.L., Byrne, M., Flood, B. \& Gonzalez, J.M., 2005, 'A study of accounting students' motives, expectations and preparedness for higher education', Revista de contabilidad-Spanish Accounting Review 12(2), 279-300.

Brown, L. \& Holloway, I., 2008, 'The adjustment journey of international postgraduate students at an English University', Journal of Research in International Education 7(2), 232-249, viewed 26 June 2009, from http://dx.doi. org/10.1177/1475240908091306

Clarence, S., 2009, 'Rethinking the role of the Writing Centre in teaching and learning strategies at the University of the Western Cape', viewed 20 June 2010, from http://utlo.ukzn.ac.za/downloads/conference/6Rethinking.pdf

Council on Higher Education, 2009, Postgraduate studies in South Africa: A statistical profile, viewed 25 November, 2009, from http://www.che.ac.za/documents/ d000195/

Council on Higher Education, 2010a, Postgraduate studies in South Africa: A statistical profile, viewed 21 June 2009, from http://www.che.ac.za/documents/d000195/

Council on Higher Education, 2010b, Higher Education monitor: Access and throughput in South African universities - Three case studies, viewed 26 June 2009, from http://www.che.ac.za/documents/d000206/

Dawson, F., 1994, Good practice for postgraduate training: The postgraduate response. Journal of Geography in Higher Education 18(3), 370, viewed 14 October 2009, from http://dx.doi.org/10.1080/03098269408709279

Department of Education, 1997, Education White Paper 3: A programme for the transformation in education in Higher Education, viewed 26 June 2010, from http://www.che.ac.za/documents/d000005/pdf

De Vos, A.S., Strydom, H., Fouche, C.B. \& Delport, C.S.L., 2005, Research at grassroots: For the social sciences and human services professions, 3rd ed., Van Schaik, Pretoria.

Earwaker, J., 1992, Helping and supporting students: Rethinking the issues. The Society for Research into Higher Education \& Open University Press, Buckingham.

Laboone, K.L., 2006, Minority students' transition experiences at a predominantly white institution. Unpublished PhD thesis, Virginia Polytechnic Institute and State University, VA (AAT 3207971)

Lovitts, B.E., 2005, Being a good course-taker is not enough: A theoretical perspective on the transition to independent research, Studies in Higher Education 30(2), 137 154, Viewed 29 June 2009, from http://dx.doi.org/10.1080/03075070500043093

Lowe, H. \& Cook, A., 2003, Mind the gap: Are students prepared for higher education?

Journal of Further \& Higher Education 27(1), 53, viewed 29 June 2009, from http:// dx.doi.org/10.1080/03098770305629

Martin, Y.M., Maclachlan, M., Karmel, T. \& Australia Department of Education, Training and Youth Affairs. Higher Education Division, 2001, Postgraduate completion rates / Yew May Martin, Maureen Maclachlan, Tom Karmel Dept. of Education, Training and Youth Affairs, Canberra, viewed 29 July 2009, from http:// www.dest.gov.au/archive/highered/occpaper/01d/01d.pdf

Ministry of Education, 2001, National Plan for Higher Education 2001, Pretoria, Ministry of Education.

Moutisios-Rentzos, A. \& Simpsom, A., 1997, Learning mathematics: Perspectives of Australian Aboriginal ... in H.L. Chick \& J.L. Vincent (eds.), 2005, Proceedings of the 29th Conference of the International Group for the Psychology of Mathematics Education 3,329-336, PME, Melbourne.

Nash, R. \& Sacre, S., 2009, Developing a framework for supporting academic literacy development in first year health undergraduates, FYE Curriculum Design Symposium 2009: Showcase, pp. 115-211, Queensland University of Technology. 
Nichols, J.D. \& Miller, R.B., 1994, Cooperative learning and student motivation.

Contemporary Educational Psychology, 19(2), 167-178, Viewed 14 October 2009, from http://dx.doi.org/10.1006/ceps.1994.1015

Ofori, R. \& Charlton, J.P., 2002, A path model of factors influencing the academic performance of nursing students, Journal of Advanced Nursing, 38(5), 507-555, viewed 14 October 2009, from http://dx.doi.org/10.1046/j.1365 2648.2002.02212.x, PMid:12028284

Poyrazli, S. \& Grahame, K.M., 2007, Barriers to adjustment: Needs of international students within a semi-urban campus community, Journal of Instructional Psychology 34(1), 28-45.

Rumsey, S., 2004, The researcher's companion: Enhanced library support for postgraduates. New Review of Information Networking 10(1), 91-95. doi:10.1080 postgraduates. New Review of Information Networking 10(1), 91-95. doi:10.1080 080/13614570412331312012
Symons, M., 2006, Starting a coursework postgraduate degree: The neglected transition, University of Queensland, viewed 25 November 2009, from http://209.85.229.132/search?q=cache:8gwMIF9q_bUJ:learning.uow.edu.au/

University of the Western Cape, 2008, UWC Prospectus, 2008, UWC, Bellville.

University of the Western Cape, 1998, Departmental research and graduate studies three year rolling plans. UWC, Bellville.

University of the Western Cape, 2007, Postgraduate enrolment and throughput, UWC, Bellville, viewed 5 July 2012 from http://www.uwc.ac.za/index.php?module=cm s\&action=showfulltext\&id=gen11Srv7Nme54_1716_1228136622\&parent=gen11 Srv7Nme54_3996_1226905605

Walters, S. \& Koetsier, J., 2006, Working adults learning in South African higher education. Perspectives in Education 24(3), 97-108. 